\title{
LA TEORÍA DE LOS ACTOS PROPIOS EN EL DERECHO DEL TRABAJO CHILENO
}

\author{
THE OWN ACTS DOCTRINE IN THE CHILEAN LABOR LAW
}

\begin{abstract}
Marcos López Oneto*
RESUMEN: La doctrina de los actos propios es una manifestación del principio general de la buena fe, que puede ser aplicada en el Derecho del Trabajo. La irrenunciabilidad de los derechos laborales es un obstáculo superable para la aplicación de tal teoría, en la medida que se distinga entre ejercicio de derechos irrenunciables versus ejercicio abusivo de los derechos irrenunciables.
\end{abstract}

Palabras clave: Buena fe, actos propios, derechos laborales, irrenunciabilidad.

ABSTRACT: The Own Acts Theory is a concrete way to realize the general principle of good faith, and potentially has application in Labour law. The non-renounceability of these labour rights is an obstacle that can be overcome by applying this theory, to the extent that there is distinction between exercises of inalienable rights versus the unlawful exercise of inalienable rights.

Key words: Good faith, own act, labour rights, inalienable rights.

\section{INTRODUCCIÓN}

La aplicación de la doctrina de los actos $\operatorname{propios}^{1}$ por la Corte Suprema (en adelante CS) en contra de las demandas entabladas por trabajadores, y también, de los que se han pretendido trabajadores (en este último caso, específicamente, en juicios de configuración de relación jurídica laboral $)^{2}$, ha generado controversia en la comunidad iuslaboralista chilena ${ }^{3}$.

\footnotetext{
Abogado, Doctor en Derecho, por la Universidad de Chile. Dirección postal: Huérfanos 1147, oficina 648, Santiago. Dirección electrónica: mlopezoneto@gmail.com

1 No existe una traducción conceptualmente equivalente al inglés y al common law. Algunos autores han intentado la traducción "the doctrine of self acts", BERNAL (2010) pp. 253-270. Como es sabido, comparativamente en el common law la institución familiarmente más próxima a la tradición continental, es el estoppel cuyo etimología propone la idea relativa a que "el acto o la conducta misma de una persona le cierran o tapan la boca (stoppeth his mouth)", PUIG (1951) p. 104.

2 En adelante utilizaremos la abreviatura TAP para referirnos a la teoría de los actos propios. La TAP, por cierto, también ha sido aplicada a favor de los intereses de los trabajadores. Un caso muy conocido fue EMPRESA DE manufacturas de Cobre S.A. (MAdeco S.A.) con Sindicatos 1 Y 2 dE LA EMPResa de MANufacturas de Cobre S.A. (1998), en STITChKin López (2009) pp. 151-162. También existen aplicaciones en casos previsionales: Escalona Pino, Simón con Superintendencia de Administradoras de Pensiones (2006), López Riedemann, Luis HeRNÁN Y Otros con Instituto de NormaLizaCión PREVISional (2006).

3 Con diversos matices y énfasis, el debate puede ser reconstruido teniendo como base la siguiente bibliografía: Gandulfo (2005) pp. 363-374; Tapia (2005) pp. 211-235; Gumucio y Corvera (2006) pp. 72-79; Opazo (2008) pp. 32-36; Ugarte (2008) pp. 90-93; Opazo (2009) pp. 69-88; CaAmaño (2009a) pp. 261-280; CaA-
} 
De una discusión sobre algo puntual, relativa a ciertos aspectos técnicos de la TAP, inmediatamente se ha pasado a una revisión de los fundamentos del Derecho del Trabajo, pues algunos han considerado que la aplicación del venire contra factum propium debilita las fronteras del ordenamiento jurídico laboral poniendo en riesgo su diferenciación y por tanto, su continuidad sistémica ${ }^{4}$.

De modo muy preliminar, es posible indicar que el arco de las tesis que discuten este asunto va desde las que niegan cualquier clase de aplicación por ser contraria a los principios y especialidad histórica del Derecho del Trabajo (tesis de la no aplicabilidad), hasta las que no distinguen reparo teórico o técnico para su aplicación en el campo jurídico laboral, fundadas en que la buena fe es un principio general del derecho, que irradia y agrega contenido material a todo el ordenamiento jurídico chileno, dentro del cual, por cierto, se encuentra el laboral(tesis de la aplicabilidad).

El aceptar o no la tesis que permite la aplicación de la TAP en materias jurídicas laborales, se ha transformado en una suerte de toma de posición no solo sobre lo que el Derecho del Trabajo chileno es, sino que también sobre lo que debería ser, confundiéndose -en la discusión- muchas veces el plano dogmático con el político jurídico laboral. Este deslizamiento del debate desde lo dogmático hacia lo político, quizás pueda ser explicado por el fuerte componente ideológico de la disciplina del Derecho del Trabajo, propio de un campo jurídico tensionado constantemente por intereses no resueltos en un modelo político social estable, cuyas fronteras como efecto lógico de las luchas de intereses, están en permanente revisión.

Pues bien, será a propósito de la jurisprudencia citada y de la crítica generada alrededor de ella, que en este artículo presentaremos una nueva contribución a la tesis de la aplicabilidad, a partir de la siguiente constatación:

Los sostenedores de la tesis de la aplicabilidad no han propuesto una solución técnica a la irrenunciabilidad de los derechos laborales, cual es el gran obstáculo que existe para su aplicación (tal como ha sido destacado por la tesis de la inaplicabilidad). En este orden de ideas, el objetivo de este trabajo es proponer una solución a la objeción planteada. La hipótesis del artículo es la siguiente: la TAP puede ser aplicada, aun en perjuicio de los derechos irrenunciables de los trabajadores, si acaso ha existido un ejercicio abusivo de tal clase de derechos. La distinción en la cual se sostiene esta hipótesis es la existente entre ejercicio no abusivo de los derechos laborales (ejercicio lícito) y ejercicio abusivo de tal clase de derechos (ejercicio ilícito).

El plan de nuestra argumentación será el siguiente: en la primera sección expondremos algunas ideas generales sobre buena fe y la TAP (I); en la segunda revisaremos la jurisprudencia laboral de la CS en materia de aplicación de la TAP (II); en la sección tercera revisaremos críticamente la doctrina jurídica laboral sobre aplicación de la TAP (III); ya acercándonos al fin de nuestra contribución, en la sección cuarta (IV), desarrollaremos nuestra tesis para, finalmente, presentar en la sección $\mathrm{V}$, algunas conclusiones.

maño (2009b) pp. 37-53; Stitchkin (2009); Gajardo (2010) pp. 15-31; Sierra (2010) pp. 141-151; Chacana (2011) pp. 5-16; Irureta (2011a) pp. 145-149; Gandulfo (2012) pp. 1-24; López Oneto (2013) pp. 61-68.

4 Caamaño (2009a) y (2009b). 


\section{UNA APROXIMACION A LA BUENA FE Y LA DOCTRINA DE LOS ACTOS PROPIOS}

\section{LA BUENA FE COMO PRINCIPIO FUNDANTE DEL ORDENAMIENTO JURÍDICO Y BASE DE LA TAP \\ La buena fe es un principio fundante del ordenamiento jurídico, es decir, se trata de} un principio sin el cual no podría llegar a constituirse aquel. LARENZ expresa esta idea cuando señala que el personalismo ético "no es suficiente para fundamentar un orden jurídico, y ni siquiera un orden jurídico-privado, si no interviniera también un elemento ético-social, este elemento es, en el Código Civil, el principio de la buena fe" ${ }^{\prime}$. El principio de la buena fe justifica así su existencia porque el surgimiento de la convivencia pacífica y mantenimiento del sistema social, precisa que "la confianza dispensada, al menos en general, no sea defraudada sino confirmada, y que, por ello la buena fe permanezca como posible en cuanto fundamento de las relaciones humanas".

Pues bien, a partir de la aproximación realizada surge la posibilidad teórica de establecer la premisa básica desde la cual se argumentará en este trabajo. Esta premisa señala que la TAP es una manifestación o forma de concretar el principio de la buena fe. Dicha noción es remontable como es sabido al derecho romano clásico (la fides bona) ${ }^{7}$, que expresaba la concepción social según la cual "es costumbre observar y legítimo esperar en las relaciones entre hombres de honor que se honre la confianza en el cumplimiento de las expectativas recíprocas" ${ }^{8}$.

\section{La bUena FE COMO LÍMITE DE los DERECHOS SUbJETIVOS}

En este orden de ideas, el principio de la buena fe es una norma jurídica básica que permite al sujeto de derecho esperar cierto rango de conductas de los demás actores del mundo social ${ }^{9}$. Otorga así derecho a esperar que, si, ciertas conductas básicas de los sujetos

\footnotetext{
5 LARENZ (1978) p. 58.

6 Larenz (1978) pp. 58-59.

7 Una reciente contribución en la cual se toca el tema: NEME (2010) pp. 309-326.

8 Neme (2010) p. 309. En derecho privado, sobre la buena fe, en general, existe una abundante bibliografía nacional y extranjera; extensa e inabordable, resultando injustificada su recopilación en un trabajo de alcances limitados como el nuestro. Algunos trabajos panorámicos sobre la materia que se han tenido presente: PUIG (1951); de los Mozos (1965); Summers (1982) pp. 810-840; Busnelli (2002); Guzmán (2002); Córdoba (2008); Zimmermann y Whittaker (2008); Corral (2009); Guzmán (2009). En sede de Derecho del Trabajo, la doctrina sobre buena fe es más acotada. Ha sido tratada, algunas pocas veces, en manuales, cursos y obras generales, a propósito de los denominados principios del Derecho del Trabajo. Así en: Plá (1990) pp. 301-318. Monográficamente como tema central de una investigación, solo algunas obras pueden ser encontradas: EsCUdERO, FrigOLA y Corbella (1996); Montoya (2001); Garcia (2001); Conde (2007); Irureta (2011a). Como sección de un libro: UGARTE (2013) pp. 228-259. En otras oportunidades y más recientemente, la buena fe no ha sido abordada, como puede ser advertido en ACKERMAN y TOSCA (2005). En general, no es un asunto doctrinariamente controvertido que la buena fe tiene plena aplicación en el Derecho del Trabajo. Lo que discute apunta más que nada a las formas de aplicación de la buena fe en materia laboral. La TAP es un ejemplo de ello.

9 En este trabajo se asume la distinción de la normas jurídicas en principios y reglas propuesta por ALEXY (2007), en donde los principios son conceptualizados como mandatos de optimización que pueden cumplirse en diferentes grados y las reglas, mandatos de cumplimiento preciso, pues poseen una estructura condicio-
} 
y que producen cierto horizonte de expectativas razonables en los demás, varían con posterioridad, aquello no puede alterar las relaciones jurídicas constituidas con anterioridad. En otras palabras, el principio de la buena fe es un límite primario al ejercicio de los derechos subjetivos, en definitiva, a la autonomía privada. Cuestión que, tal como ha mostrado BARROS, tratándose de un orden privado sustentado en el mentado principio es en último término "una exigencia del principio kantiano de que la libertad de unos debe resultar compatible con la libertad de los demás según una regla general” ${ }^{10}$. Pero se trata, lógicamente, de un límite externo a la autonomía de la voluntad.

En efecto, puesto que la buena fe es un principio constitutivo del ordenamiento jurídico, es decir, uno de los vértices del marco normativo más general que permite la complejización del ordenamiento, es que opera como un límite externo al ejercicio de los derechos subjetivos, ya que el contenido de cada derecho subjetivo en particular constituye su primer o natural límite, una especie de límite interno ${ }^{11}$. En tanto límite externo, la buena fe suele ser concretizada mediante la doctrina del abuso de derecho, entendida esta "como un correctivo excepcional, con fundamento en la moral y las costumbres, al ejercicio legítimo de los derechos" 12 .

El abuso de derecho opera como un correctivo excepcional "cuando el comportamiento del titular atenta contra estándares mínimos de conducta, que no es posible expresar en modelos de conducta que establezcan condiciones precisas de su aplicación ${ }^{13}$. Y es que "en los límites del derecho privado se encuentra una invocación a las costumbres y a la razón compartida espontáneamente por la comunidad" 14 . Por tal razón, concluye BARros que dichos modelos o patrones conductuales, solo pueden expresarse a través de cláusulas generales, como las "buenas costumbres" (arts. 1461 y 1467) y en la "buena fe" (art. 1546). Pero invocar tales conceptos generales e indeterminados, "arriesga comprometer la seguridad jurídica”, lo cual ha contribuido a que la doctrina del abuso de derecho tienda a "concretarse en grupos de casos típicos", a saber: a) ejercicio de un derecho con el solo propósito de causar daño a otra persona, b) extrema desproporción entre el interés del titular y el efecto negativo que produce en otra persona el ejercicio del derecho, c) los actos propios, d) el ejercicio de un derecho adquirido de mala fe, e) la desviación del fin de un derecho potestativo y f) el abuso de formas o instituciones jurídicas ${ }^{15}$.

En síntesis, todo lo expuesto hasta aquí sugiere que:

(a) La buena fe es un principio constitutivo del ordenamiento jurídico. Su estructura normativa es indeterminada si se compara con una norma tipo regla, donde los supuestos de hechos y consecuencias jurídicas están delimitados positivamente.

nal consistente en un supuesto de hecho y una consecuencia jurídica determinada.Una revisión del tema en perspectiva jurídica laboral Martin (2003); López Oneto (2013) pp. 40-136. Para una visión general, Alexy (2007) pp. 63-149; AtienZa y Ruiz (2007) pp. 23-68.

10 Barros (1999) p. 12.

11 Barros (1999) pp. 12, 14, 15 y 19.

12 Barros (1999) p. 15.

13 Barros (1999) p. 19.

14 Barros (1999) p. 19.

15 En profundidad, Barros (2006) pp. 632-654. También, Díez-Picazo (2011) pp. 62-63. 
(b) Dado que la buena fe es un principio constitutivo del ordenamiento jurídico, el ejercicio de los derechos subjetivos que otorga tal ordenamiento a los sujetos se encuentra limitado en función de aquella, pues el ejercicio de un derecho no puede ir en contra de los principios que lo sustentan.

(c) El fundamento último de la TAP es el principio de la buena fe. La buena fe en su rol de principio constitutivo del ordenamiento jurídico, como se expresó, opera también como límite externo al ejercicio de los derechos subjetivos. Sin embargo, como todo principio, tiene una formulación abstracta e indeterminada, ya que no posee con la misma claridad los supuestos de las normas jurídicas tipo regla (dado C entonces S), cuestión que dificulta su aplicación directa. Por esta razón, en general, para aplicar el principio de la buena fe-como límite externo al ejercicio de los derechos subjetivos-, se precisan de construcciones doctrinales que permitan su aplicación al caso concreto. De esta manera, la TAP se erige como una aplicación del principio de protección a la buena fe, en casos típicos de inconsistencia conductual de los sujetos de derecho que afectan la confianza básica que permite desarrollar una relación jurídica eficaz.

\section{LA FORMULACIÓN ESTÁNDAR DE LA TAP}

La idea general en torno a la cual se ha construido esta doctrina es el imperativo de restarle efectos jurídicos a la conducta actual de una persona que contradice lo obrado por ella misma en el pasado. Entre las dos conductas, debe prevalecer la primera, si acaso fue lícita. La segunda conducta, aunque externamente parezca lícita, si contradice la primera, debe ser desechada porque vulnera la buena fe y la confianza que deben guiar relaciones jurídicas contractuales. Así las cosas, quien contradice una conducta anterior, vulnera la buena fe, y en consecuencia su acción puede ser considerada como abusiva, acarreando, eventualmente, su ineficacia. Esta conceptualización de la TAP - por cierto que con matices- es comúnmente aceptada por los más diversos autores ${ }^{16}$.

Siguiendo a Corral, en cuanto a los requisitos técnicos jurídicos que se exigen para la correcta aplicación de la TAP y que son comúnmente mencionados por la doctrina, aceptaremos por tales la concurrencia copulativa de: $\left(1^{\circ}\right)$ una primera conducta que sea jurídicamente relevante, válida y voluntaria; $\left(2^{\circ}\right)$ que esta conducta produzca objetivamente un estado de hecho que permita generar confianza o expectativas legítimas en otra persona; $\left(3^{\circ}\right)$ una segunda conducta que sea contradictoria o incoherente con la primera y con ella se pretenda ejercer un derecho, facultad o pretensión; y, por último, (4º) que exista identidad entre el sujeto que desarrolló la primera conducta y el que ahora pretende desconocerla con un hecho contrario. A este conjunto de requisitos los denominaremos la doctrina estándar ${ }^{17}$. Todas nuestras argumentaciones sobre aplicación de la TAP en el Derecho del Trabajo chileno, estarán formuladas teniendo como referencia al modelo estándar recién

16 Así en España: Puig (1951); Díez-Picazo (1963); Jaramillo (2012). También en Alemania: Wieacker (1977). En Argentina: Borda (2005); López Mesa y Rogel (2005); López Mesa (2009) pp. 189-222. Y lo mismo en nuestra doctrina: López Santa María (1985) pp. 33-52; Ekdahl (1989); Fueyo (1990); Rivas (1991); Pardo (1991-1992) pp. 49-69; Romero (2003) pp. 167-172; Barros (2006) pp. 637-640; Salah (2008) pp. 189-202; Romero (2010) pp. 69-79; Corral (2010a) pp. 19-33; Corral (2010b) pp. 103-139.

17 Corral (2010b) p. 106. 
descrito. Asimismo, si se revisa la doctrina iuslaboralista chilena sobre el tema, podrá advertirse que también comprende la TAP en su versión estándar ${ }^{18}$.

\section{LA JURISPRUDENCIA DE LA CORTE SUPREMA SOBRE TEORÍA DE LOS ACTOS PROPIOS EN ASUNTOS JURÍDICOS LABORALES ${ }^{19}$}

\section{BASE JURISPRUDENCIAL ANALIZADA}

Los primeros casos en que CS aplica la TAP en contra de las pretensiones de los trabajadores (a lo menos, desde el año 2005) ${ }^{20}$, fueron Labra Guerrero, Franklin del Carmen con Ingenieros Consultores Asociados S.A. [2005] y Muñoz Vilches, Paola Andrea con Inmobiliaria El Rebaño Limitada [2005]. Será a partir de esos casos, que la CS irá desarrollando una línea jurisprudencial de aplicación de la TAP ${ }^{21}$.

\section{ANÁLISIS DE LA JURISPRUDENCIA}

Se analizará la jurisprudencia desde dos perspectivas relacionadas entre sí en términos de constituir una unidad analítica.

En primer lugar, nos detendremos en el contenido argumentativo que el Tribunal utiliza para fundamentar la aplicación de la TAP. Por contenido argumentativo entenderemos el conjunto de ideas y razonamientos que utiliza el Tribunal para justificar la aplicación de la TAP.

En segundo término, observaremos la jurisprudencia a partir de la distinción entre argumentos que conforman la ratio decidendi del fallo, y aquellos esgrimidos en carácter de obiter dicta. Es decir, distinguiremos cuándo la Corte Suprema acude a la TAP como argumentación fundamental del pleito, de aquellos casos en que solo se acude marginalmente a ella.

\footnotetext{
18 La versión más representativa en CAAMAÑo (2009a) pp. 266-273, quien básicamente trabaja el tema con las presentaciones de WiEACKer (1982), EDKHAL (1989) y BORDA (2005) quienes abordan la TAP en materia civil.

19 La investigación jurisprudencial se acotó al período 2005-2013, limitándose a fallos de casación y unificación de jurisprudencia. Con todo, prácticamente la totalidad de los fallos son de casación. En sede de unificación solo se encontró una sentencia relacionada con el tema que toca marginalmente esta materia: GODOY CON RED TELEVISIVA MEGAVISIÓN S.A. (2012).

20 Se hace presente que, a nivel de Corte de Apelaciones, existe un fallo anterior, a saber: el de 27 de noviembre de 2000, Rol No 913-2000,: AZÓCAR TAPIA, LUIS CON AZÓCAR S.A. (2000).

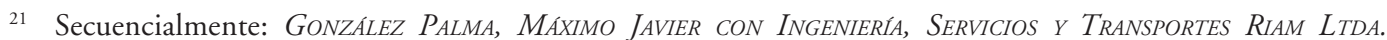
(2006); Gumucio Rivas, Juan con EMpresa Metropolitana de Obras Sanitarias (2006); Mujica VARAS, EDUARDo con Corporación de Televisión Universidad Católica (2006); Alcayaga Sasso, Juan con Corporación de Tele-

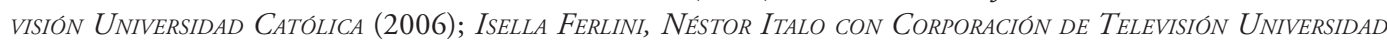
Católica de Chile (2006); Silva Sour, Héctor Armando con Lexis Nexis Chile Limitada (2006), Monasterio Riquelme, Eduardo Antonio con red de Televisión Chilevisión ((2007); Bustos Rubilar, José Rafael con Corporación de Televisión Universidad Católica (2007); Inspector Provincial del Trabajo de Valdivia con Aserraderos Paillaco S.A.(2007); Opazo Corvalá, Jaime con Axis Group S.A. y Econet S.A. (2007); Santander Lizana, María con Corporación de TeleVisión Universidad Católica (2007); KLiche Antonini, Walter con Corporación de Televisión Universidad Católica (2007); Muñoz Calderón, María Soledad con Caritas Chile (2008); Pacareu Gay, Natalia con Universidad Mayor (2008); Yañez Arriagada, Ximena Alejandra con Campos DEPORTIVOS LLANCOLEN S.A. (2008).
} 
Se justifica esta unidad analítica porque la comprensión de la jurisprudencia exige no solo la descripción lineal de los argumentos sino que también la determinación del peso decisorio que el Tribunal, en el discurso jurisdiccional, le asigna a cada uno de ellos.

\subsection{La argumentación de la Corte Suprema en la base jurisprudencial analizada}

\subsubsection{El contenido argumentativo}

En todas estas aplicaciones jurisprudenciales de la TAP no se observó un marco teórico que justifique su utilización en el campo jurídico laboral, haciéndose cargo de incardinar la TAP y sus efectos, en el contexto normativo que generan los principios de rectores del Derecho del Trabajo. Así por ejemplo, no se observa la existencia de argumentos o construcciones conceptuales jurisprudenciales que permitan comprender las condiciones que permitirían la derrota de los principios jurídicos laborales (protección, en clave de irrenunciabilidad de los derechos laborales), frente al de la buena fe plasmado en la TAP 22 .

Pueden ser considerados ejemplos típicos de esta forma de invocación jurisprudencial de la TAP, que se repite en todos los casos inspeccionados, y que podríamos calificar como de asistemática, por no ser fruto de una reconstrucción dogmática jurisprudencial del ordenamiento, los siguientes:

a. "Cuarto: Que, en primer término, para dilucidar la discusión planteada en estos autos, es útil recurrir a la denominada Teoría de los Actos Propios, basada en la noción que a nadie le es lícito ir contra sus propios actos anteriores que expresan la voluntad del sujeto y que se funda, en definitiva, en el principio más general de la buena fe, la que, ciertamente, tiene plena cabida en el ámbito laboral de que se trata" ${ }^{23}$.

b. "Séptimo: Que a propósito de la buena fe con la que deben cumplirse los contratos, útil resulta traer a colación la denominada Teoría de los Actos Propios, según la cual si un sujeto define su posición jurídica mediante el desarrollo de determinadas conductas, no le es lícito desconocer, posteriormente, sus propias actuaciones, de modo que si la demandante durante casi tres años concurrió a general una relación laboral de plazo fijo, a través de las sucesivas suscripciones de contratos de esa naturaleza, con sus correspondientes finiquitos al término de cada período, no es dable que ahora pretenda desconocer dichos acuerdos, aludiendo a una realidad distinta y a derechos irrenunciables" 24 .

Las ideas e ilustraciones de esta sección sugieren que los fallos aplican la TAP pero no justifican completamente por qué dicha doctrina resulta compatible con los principios

\footnotetext{
22 Son estas aplicaciones de la TAP las que han generado controversia no solo en la comunidad iuslaboralista, sino que incluso han promovido una crítica más general que ha calificado a la señalada jurisprudencia como modelo de lo que se denomina "teoría expansiva del acto propio", entendido como parte de un proceso de "vulgarización del Derecho", signado por el uso de figuras o doctrinas de contornos pocos precisos, superponiéndose "con otras instituciones o razones de mayor carácter técnico y mejor fundamentadas, ampliando en alguna medida, los supuestos operativos de las normas y redundando en ciertas consecuencias jurídicas sin mayor justificación”, GANDULFO (2005) p. 364.

23 Muñoz Vilches, Paola Andrea con Inmobiliaria El Rebaño Limitada (2005).

24 Muñoz Calderón, María Soledad con Caritas Chile (2008).
} 
y estructura garantista general del Derecho del Trabajo, cuyo eje es la protección del trabajador. Al no hacerlo, la incardinación de la TAP en dicha rama del derecho no resultaría completamente justificada.

\subsubsection{Ratio decidendi/Obiter dicta}

No obstante que está en constante discusión doctrinal, la distinción entre ratio decidendi y obiter dicta es una herramienta de análisis de precedentes comúnmente aceptada en la doctrina comparada ${ }^{25}$. Su utilidad se justifica porque permite establecer el peso de los argumentos en el discurso jurisdiccional, distinguiendo el precedente de todo aquello que no lo es ${ }^{26}$.

En términos generales se ha entendido por ratio decidendi el conjunto de racionamientos y argumentaciones contenidos en el fallo que fundamentan de manera directa la resolución del conflicto y que constituyen el precedente. Y, por obiter dicta, en cambio, el conjunto raciocinios, ilustraciones, recursos tópicos o retóricos que se utilizan en la sentencia que, pudiendo contribuir a la persuasión, sin embargo no fundamentan de manera directa la resolución del conflicto y no constituyen el precedente ${ }^{27}$. Así, y como dice WhitTaker "obiter dicta son todas aquellas proposiciones de Derecho en las sentencias que carecen de la fuerza de ratio"ns.

La distinción ratio decidendi/obiter dicta, la utilizaremos para los efectos de determinar el peso argumentativo que, en sus sentencias, la Corte Suprema asigna a la TAP. Aquel aspecto resulta extremadamente pertinente para el análisis crítico, porque, si la CS utiliza la TAP solo como obiter dicta, entonces no resulta correcto afirmar que la CS ha resuelto o fallado esas causas utilizando como fuente normativa la TAP, ya que tal utilización no es ratio, esto es, no es el fundamento directo del fallo.

\subsection{Revisión de la jurisprudencia con la distinción ratio decidendilobiter dicta}

En el conjunto de las sentencias de casación inspeccionadas es posible distinguir 5 en las cuales la CS utiliza la TAP como obiter dicta, mediante el uso de fórmulas tales como: "que la pretensión de la demandante debe rechazarse, además, por aplicación de la teoría de los actos propios"; "es en ese ámbito privativo que se aplican principios y construcciones doctrinarias como la teoría de los actos propios"; "que, para corroborar lo anterior útil resulta recurrir a la denominada teoría de los actos propios"; "que a lo anterior cabe agregar que al respecto es dable considerar la denominada teoría de los actos propios", o bien, "que,

\footnotetext{
25 Garner (2004), pp. 1102 y 1290; López Medina (2006) pp. 216-264; Cross y Harris (2004); Legarre y Rivera (2006) pp. 119-122; Romero (2011) pp. 342-343.

26 Romero (2011) p. 342. Pero la definición de precedente tampoco es unívoca. En la doctrina inglesa, por ejemplo, se ha entendido por algunos que precedente es "el conjunto de normas con arreglo a los cuales los fallos anteriores pueden ser vinculantes para el proceso decisorio posterior”, WhitTaKer (2008) p. 50. Así se dice que la "ratio decidendi tiene la aptitud de vincular el proceso de decisión de un tribunal posterior (dependiendo de las posiciones relativas de los tribunales en la jerarquía), mientras que el obiter dicta no obliga aunque tiene cierta “autoridad persuasiva”, Whittaker (2008) p. 49. También en: Legarre y Rivera (2006) pp. 113-119.

27 López Medina (2006) pp. 216-243.

28 WhitTAKer (2008) p. 50.
} 
además de lo relacionado, resulta útil recurrir a la denominada Teoría de los Actos Propios".

Lo que caracteriza a estos casos, y es el motivo porque los clasificamos como obiter dicta, es que la Corte decide el asunto básicamente acudiendo a otros argumentos diferentes de la TAP; teoría de la cual podría prescindirse e igualmente arribarse a la misma conclusión. De ahí, por ejemplo, el uso de la fórmula verbal "corroborase", dando a entender que ya tiene (o viene) decidido el caso por otras razones.

En los restantes 10 casos, en los cuales es posible distinguir una especie de uso de la TAP como ratio decidendi, cabe tener presente que no se lo hace presentando dicha doctrina como la única fuente normativa, sino que como una pieza argumental más dentro de un conjunto de razones. Por esta circunstancia, se estima que aun cuando se utiliza la TAP como ratio decidendi, el hecho que lo haga en las referidas condiciones, torna esta aplicación menos fuerte a que lo hiciera invocándola solo a ella como norma decisoria litis. Esta forma de uso de la TAP, caracterizada porque es una pieza más de un conjunto mucho más amplio de argumentos para decidir una controversia, se define como una ratio decidendi compleja y débil ${ }^{29}$. Compleja, porque la TAP no es el único argumento y débil, además, porque solo se menciona o invoca, sin una fundamentación sobre su preeminencia por sobre los principios que gobiernan el Derecho del Trabajo.

\section{REVISIÓN CRÍTICA DE LA DOCTRINA JURÍDICA LABORAL SOBRE APLICACIÓN DE LA TAP}

En la sección II de este artículo se analizó la base jurisprudencial. Las conclusiones a las cuales se arribó gracias a ese examen fue que la base argumentativa de los fallos es asistemática; que la TAP se aplica como obiter dicta y cuando se le aplica como ratio decidendi, esta resulta compleja y débil.

Teniendo presente lo anterior, se examina a continuación la doctrina iuslaboralista sobre aplicación jurisprudencial de la TAP.

\section{OBSERVACIÓN GENERAL}

Con un cierto parecido de familia - por utilizar una conocida expresión de Wittgenstein ${ }^{30}$ - plausible resulta destacar que el arco de las tesis que discuten este asunto va desde las que admiten, con mayor o menor intensidad, la aplicación de la TAP en el campo jurídico laboral, fundadas algunas en que la buena fe es un principio general del derecho, que irradia y agrega contenido material al ordenamiento jurídico chileno, dentro del cual, por cierto, se encuentra el laboral (tesis de la aplicabilidad); hasta las que niegan cualquier clase de aplicación por ser contraria a los principios y especialidad histórica del Derecho del Trabajo (en adelante tesis de la inaplicabilidad).

\footnotetext{
29 La presencia de la TAP como fundamento de una decisión jurisdiccional en el contexto de un conjunto de otros argumentos de derecho, sin relación o con una muy débil relación de imbricación lógica y material entre ellos, también ha sido denominada "estrategia del apilamiento argumentativo", Gandulfo (2012) p. 22.

30 Wittgenstein (2008) pp. 87-93.
} 


\section{LAS TESIS EN DISPUTA}

Tal como se adelantó, hay dos tesis en disputa: la tesis de la aplicabilidad de la TAP (1); y la tesis de la inaplicabilidad de la TAP (2). Los límites de este artículo impedirán hacer una revisión extensa y en detalle de estas dos corrientes doctrinarias. Por lo anterior, se ha optado por presentar una visión general de cada una de ellas, a partir del establecimiento de algunas notas distintivas que las caracterizan.

\subsection{La tesis de la inaplicabilidad ${ }^{31}$}

En general, los sostenedores de esta tesis consideran que la aplicación del venire contra factum propium debilita las fronteras del ordenamiento jurídico laboral poniendo en riesgo su diferenciación y por tanto, su continuidad sistémica. Alegan que la especialidad histórica del Derecho del Trabajo, cuyo eje sería solo la protección al Trabajador, impediría su aplicación, puesto que se trata de una teoría civilista construida para resolver problemas en el contexto de relaciones jurídicas patrimonialistas dominadas por la ficción de la igualdad de las partes, donde el orden público - por regla general- no pasa por la protección especial de uno de los contratantes. Asimismo puntualizan que la CS la aplica incorrectamente, pues resulta estructuralmente imposible que pueda cumplirse el primer requisito de aplicación de la teoría, a saber, que la primera conducta sea jurídicamente relevante, válida y voluntaria. Argumentan que, dado que los derechos laborales son indisponibles, por más que un trabajador haya incurrido en una conducta que contradice la primera, si aquello implicó fácticamente la renuncia a derechos irrenunciables, no ha podido producir efectos jurídicos adversos para el Trabajador.

Mas en general, la tesis de la inaplicabilidad es una manifestación de las doctrinas que denuncian la reprivatización del Derecho de Trabajo, una huida hacia formas civiles que se tenían por superadas ${ }^{32}$.

Sistemáticamente la crítica que la tesis de la inaplicabilidad formula a la jurisprudencia analizada, puede ser caracterizada por las siguientes notas distintivas: (A) en sus alegaciones no utilizan la herramienta analítica obiter dictal ratio decidendi; (B) focalizan su ataque invocando la especialidad histórica del Derecho del Trabajo como factor de inaplicabilidad de la TAP, y, (C) refuerzan lo anterior, señalando que el origen o matriz civilista de la TAP, impide que pueda ser utilizada en el Derecho del Trabajo. A continuación las desarrollamos sumariamente:

31 Entre otros, la suscriben: Gumucio y Corvera (2006) pp. 72-79; Ugarte (2008) pp. 90-93; CaAmaño (2009a) pp. 261-280; (2009b) pp. 37-53; ChACANA (2011). En una posición menos intensa y más reflexiva, TAPIA (2005) pp. 232-234, quien señala que al menos dos de los tres elementos que requiere la aplicación de la TAP, resultan discutibles. "El primero de ellos, cuando se trata de una conducta relevante y eficaz, en orden a que, reconocido el hecho de haberse verificado una situación de trabajo dependiente, este no ha generado los efectos propios de una relación laboral; el segundo, en cuanto se trata del ejercicio de derechos subjetivos que pueden entrar en colisión con otros, en la especie, aquellos que son propios del contrato de trabajo", TAPIA (2005) p. 234.

32 Mangarelli (2008) pp. 105-123 A nivel más general, y sobre huida del "Derecho del Trabajo" hacia formas civiles o hacia su individualización, la bibliografía es heterogénea y abundante. Algunos textos fundacionales: Rodríguez-Piñero (1992) pp. 85-94; Blasco (1995); Valverde (1990) pp. 236-259. 
(A) En esta familia de tesis, se observan críticas a los fallos de la Corte Suprema sin utilizar las herramientas analíticas que permitan determinar si la TAP se invoca como ratio decidendi u obiter dicta, cuestión de capital importancia para determinar el peso argumental y decisorio de la teoría criticada en la resolución judicial. Por lo mismo, estos autores no advierten que las aplicaciones de la TAP, en los citados fallos, son parte de una ratio decidendi compleja que no recurre única y exclusivamente a la TAP como pilar jurídico básico de la fundamentación. Por lo anterior, las críticas que vienen desde ese lado de la doctrina, son incompletas pues omiten pasos y elementos esenciales del análisis.

(B) Otra nota distintiva de las tesis de la inaplicabilidad, formulada de diversas maneras, es la invocación a la especialidad histórica del Derecho del Trabajo, cuestión que impediría que se le aplicaren doctrinas civilistas, como sería la TAP ${ }^{33}$.

Sin embargo, como veremos, la apelación a la especialidad histórica del Derecho del Trabajo, explica la génesis del Derecho del Trabajo, pero no su actual constitución positiva o incompatibilidad con la TAP. Esto, por las siguientes razones:

(B.1) El derecho es una ciencia hermenéutica, en donde la comprensión (conocimiento) es fruto de la concurrencia simultanea (compleja) de varios elementos que permiten su evolución y desarrollo. Por consiguiente, concebir el Derecho del Trabajo solo a partir de su especialidad histórica es objetable porque lo presenta constituido de una vez y para siempre; inmune e inelástico a los cambios y evoluciones propias de toda institución.

(B.2) El Derecho del Trabajo, qué duda cabe, es protector del trabajo y del trabajador. Pero su especialidad histórica, cumple una función mucho más estructural: busca la paz social que se obtendría mediante la conciliación entre capital y trabajo en la perspectiva de asegurar la producción y reproducción material e ideológica de la sociedad capitalista.

El reconocido iuslaboralista hispanoamericano, MONEREO, al respecto ha escrito que: "El principio de libre empresa en el marco del sistema de economía social de mercado actúa como condicionante económico del derecho del trabajo, pues si bien el derecho del trabajo procura conseguir todo lo que es deseable socialmente, no puede realizar más que lo que es posible económicamente" 34 .

En otras palabras, lo que Monereo está tratando de mostrar es que el principio de protección del trabajador encuentra su límite material y jurídico en el contexto del orden económico capitalista vigente, en términos tales que la mejora de las condiciones de trabajo no puede anular la capacidad de funcionamiento y por consiguiente de supervivencia del propio modo de producción capitalista. El Derecho del Trabajo expresa esa realidad de la cual "se infiere la existencia contradictoria (en permanente contraposición dialéctica) entre dos grandes principios que vienen a caracterizar al derecho del trabajo informando sus instituciones e inspirando y condicionando a los verdaderos principios aplicativos e interpretativos de sus normas jurídicas, tales principios básicos son, por simplificar, reconducibles a dos: el principio de protección del trabajador (el favor laboratoris que, entronizado en el derecho del trabajo, determina el carácter tuitivo del mismo) y el principio de libertad de

33 CAamaño (2009a) pp. 261-280; y CaAmaño (2009b).

34 Monereo (1996) 
empresa en el marco del sistema de economía social de mercado (principio este que en no poca medida se corresponde con el conocido principio de conservación y rendimiento de la empresa) que tutela el interés del empleador al condicionar económicamente el alcance del principio de protección"35.

La especialidad histórica del Derecho del Trabajo, por consiguiente, no significa la configuración de un ordenamiento laboral aislado o incomunicado con el resto del ordenamiento jurídico capitalista, ergo, no implica una negación de los fundamentos del Derecho Privado. Todo lo contrario, es parte de aquel y persigue los mismos fines estructurales de reproducción de la sociedad capitalista. Su autonomía, por tanto, no significa negación de los supuestos o principios fundamentales del ordenamiento general, como es el principio de protección de la buena fe y la sanción al ejercicio abusivo de los derechos. Esta afirmación en ningún caso implica negar el particularismo del Derecho del Trabajo, de sus regulaciones, dentro de las cuales, por cierto, se encuentra la irrenunciabilidad de los derechos laborales. Pero dicha irrenunciabilidad no es absoluta, porque todo derecho reconoce límites y porque, además, ora en nombre de la irrenunciabilidad, no pueden ampararse situaciones que evidentemente entrañan un abuso de derecho. Por lo demás, en la invocación jurisprudencial de la buena fe subyace un innegable apego al principio de la seguridad jurídica.

C) En tercer lugar, es posible advertir como otra nota distintiva en las tesis de la inaplicabilidad, la siguiente idea: el origen o matriz civilista de la TAP, impide que esta pueda ser utilizada en materia laboral, precisamente por la especializada histórica del Derecho del Trabajo. Este argumento es objetable. Desde luego por una razón muy simple: porque, si así fuere, entonces lisa y llanamente no podríamos concebir la estructura del contrato de trabajo cuyo marco jurídico más general son las normas del Código Civil, en las cuales se establecen sus requisitos de existencia y validez, así como los conceptos y tipos jurídicos fundamentales que configuran la teoría de los actos jurídicos. Las normas que regulan la nulidad de los contratos, ciertamente que no las encontraremos en el Código del Trabajo, como tampoco la definición de contrato consensual ${ }^{36}$. Luego es evidente que la comprensión dogmática del contrato de trabajo supone la comprensión previa del contrato en general, cuyas normas generales están contenidas en el Código Civil ${ }^{37}$.

\footnotetext{
35 Monereo (1996) p. 34. La concepción de Derecho del Trabajo como mecanismo de defensa del Estado Capitalista Liberal, es prácticamente indiscutida en la doctrina. Aparte del ya citado Monereo, puede consultarse un análisis clásico del tema también en: PALOMEQue (2011).

36 El artículo 9 del Código del Trabajo dice expresamente que el "contrato de trabajo es consensual". Sin embargo, no define contrato consensual. La definición de contrato consensual como sabemos, la encontramos en la parte final del artículo 1443 del Código Civil.

37 Hay muchos casos de comunicabilidad del Derecho del Trabajo con otras ramas del derecho. Por ejemplo, con la recepción del denominado principio de adecuación social, principio que originalmente correspondió a una incorporación dogmática del penalista Hans Wenzel, DE LA VILLA (2003) pp. 393-416. O el principio civil de la conservación del negocio, que se aplica también en el Dereho del Trabajo, PLÁ (1990) p. 154.
} 


\subsection{Tesis de la aplicabilidad ${ }^{38}$}

En la familia de las tesis de la aplicabilidad, el foco del análisis se centra en la reconstrucción dogmática del sistema, en la perspectiva de incardinar la TAP en la estructura normativa del Derecho del Trabajo. Su fin es mostrar cómo la estructura normativa del Derecho del Trabajo permite la aplicación de la TAP. Inevitablemente, por tanto, se abocan a la revisión del derecho positivo del trabajo. Por lo general lo que se propone para tal fin, es una conceptualización de la buena fe como principio general del ordenamiento jurídico que irradia estructuralmente todos sus sectores, entre ellos el laboral ${ }^{39}$.

El gran obstáculo de fondo que debe ser resuelto para aplicar la TAP en asuntos jurídicos laborales, es la irrenunciabilidad de los derechos laborales mientras subsista el contrato de trabajo, institución prevista en el artículo $5^{\circ}$ del Código del Trabajo. Hasta el momento, en la familia de tesis de la aplicabilidad no se encuentran respuestas directas a esta interrogante. Como se indicó al comienzo, el objeto de este trabajo es contribuir a encontrar esa respuesta. Por lo anterior, analizaremos las tesis de la aplicabilidad, enfocándonos mayormente en el tema de la irrenunciabilidad de los derechos que otorgan las leyes laborales. Dicho esto, por el lado de las tesis de la aplicabilidad, es posible levantar las siguientes notas distintivas:

A) En esta familia de tesis se observan diferentes soluciones a la barrera que la irrenunciablidad de los derechos laborales instala en el espacio-tiempo jurídico para impedir, prima facie, aplicar la TAP.

A1) Así GajARdo (a propósito de la discusión sobre configuración de relaciones laborales iniciadas al amparo formal de contratos a honorarios), señala que no comparte la opinión de algunos autores que defienden la laboralización en tales casos, porque parten "de una base errada: la incapacidad del trabajador para tomar sus propias decisiones, que favorecen la imposición unilateral de las condiciones de trabajo, como si se quisiera defenderlo de sí mismo" ${ }^{40}$. Y agrega, además, "que la irrenunciabilidad de los derechos laborales y la presunción de relación laboral habrán de producir sus efectos propios, en la medida que estemos ante derechos efectivamente adquiridos y no ante meras expectativas" ${ }^{21}$.

Nos parece que los argumentos de GAJARDO son objetables, al menos, por las siguientes razones: la irrenunciabilidad de los derechos laborales efectivamente significa legal y constitucionalmente que hay ciertas decisiones que los trabajadores y los empleadores, simplemente no pueden tomar. Pero no lo pueden hacer, no porque la Ley los considere incapaces o pretenda defenderlos de sí mismos, sino porque entiende que existe un interés público que impide el tráfico jurídico de ciertos bienes laborales protegidos. Se trata de un tema de orden público laboral ${ }^{42}$, de configuración del marco normativo de la sociedad que,

38 Entre otros: Opazo (2008a) pp. 32-36; Opazo (2009b) pp. 69-88; Gajardo (2010) pp. 15-31; Sierra (2010); Irureta (2011a) pp. 145-149; López Oneto (2013) pp. 61-67.

39 Opazo (2009) pp. 69-88; Gajardo (2010) pp. 15-31; Irureta (2011) p. 146.

40 Gajardo (2010) p. 25.

41 Gajardo (2010) p. 25.

42 Para una revisión del tema: IrUReTa (2006). 
en parte, como sabemos, se realiza mediante la técnica del establecimiento de prohibiciones, irrenunciabilidades o declarando incomerciables ciertos bienes ${ }^{43}$.

El legislador, al desarrollar el programa constitucional, prohíbe la renuncia de los derechos laborales mientras se encuentre vigente el contrato de trabajo, así como también prohíbe otras clases de negocios jurídicos en los diferentes sectores o campos de ordenamiento jurídico constituido. Por lo expuesto, la renuncia de los derechos laborales irrenunciables puede ser clasificada típicamente como un caso de objeto ilícito.

Por otra parte, la distinción que propone GAJARDO para superar el obstáculo de la irrenunciabilidad, entre derechos efectivamente adquiridos y meras expectativas, parece no tomar en consideración que la naturaleza del orden público laboral supone restarle eficacia a las actuaciones de las personas, más allá de cuál haya sido la real intención de las partes. Porque si, en la realidad, se dan y se logran acreditar los supuestos fácticos de una relación laboral, pues entonces el Tribunal del Trabajo deberá tenerla por configurada.

En esa línea de argumentación, SIERRA tiene razón en parte cuando postula que el derecho irrenunciable por excelencia del Derecho del Trabajo consiste en que una relación se califique como laboral si se cumplen los presupuestos para ello. Por consiguiente, la circunstancia que el trabajador haya celebrado un contrato civil de honorarios, emitido boletas de honorarios y tributado como trabajador independiente, no ha podido implicar renunciar al derecho de solicitar a un Tribunal que califique de laboral la relación, si acaso se dieron los supuestos fácticos que permiten configurarla. Lo anterior, por cuanto, el orden público laboral limita la voluntad de las partes.

A2) Volviendo a Sierra, autor al cual también incluimos dentro de esta familia de tesis, porque no descarta que la aplicación de la TAP sea posible en el Derecho del Trabajo, pues no distingue obstáculos estructurales para ello, postula que la TAP puede aplicarse "en el ámbito laboral, en cuanto no implique disposición o renuncia de derecho legal o convencional reconocido". Y "el derecho irrenunciable por excelencia del Derecho del Trabajo consiste precisamente en que una relación se califique como laboral” ${ }^{4}$.

La tesis de Sierra que, como se decía, compartimos en parte, presenta un inconveniente metodológico en su fundamentación, a saber: no introduce en el análisis la pregunta sobre los límites a los derechos. En efecto, para sostener la irrenunciabilidad del derecho a que una relación se califique como laboral, es preciso que se justifique primero por qué un derecho no podría ser limitado en su ejercicio, distinguiendo si se trata de derechos fundamentales o simplemente legales. Puesto que ese paso se omite, la crítica de Sierra no puede ser completamente aceptada. Nuestra contribución irá encaminada a resolver ese problema.

B) Finalmente se ha aislado también como nota distintiva de la familia de la aplicabilidad, la no utilización de herramientas analíticas que permitan determinar si la TAP se invoca como ratio decidendi u obiter dicta en los fallos que son parte de la controversia. Como ya se resaltó en párrafos anteriores, el correcto de análisis de la jurisprudencia exige

\footnotetext{
43 Así en la Ley de Protección al Consumidor, No 19.496, "artículo 4º.- Los derechos establecidos por la presente ley son irrenunciables anticipadamente por los consumidores"; y en la Ley de Arrendamiento de Predios urbanos, No 18.101, "artículo 19.- Son irrenunciables los derechos que esta ley confiere a los arrendatarios.

44 Sierra (2010) p. 151.
} 
el uso de herramientas que permitan determinar el peso de los argumentos en el discurso jurisdiccional. Una vez determinado el peso o importancia del argumento, es posible criticar correctamente su uso en el discurso.

\section{DE LA APLICABILIDAD DE LA TAP EN EL DERECHO DEL TRABAJO CHILENO}

La hipótesis que se ha propuesto dice que TAP puede ser aplicada, aun en contra de los derechos irrenunciables de los trabajadores, si acaso ha existido un ejercicio abusivo de tal clase de derechos. La distinción en la cual se sostiene esta hipótesis es la existente entre ejercicio no abusivo de los derechos laborales y ejercicio abusivo de tal clase de derechos. A continuación, presentamos sintéticamente nuestra argumentación:

1. Es necesario primero establecer que la aplicación de la TAP, como ha sido reconocido por la doctrina comparada, siempre es excepcional, no solo en asuntos laborales, sino que en todo ámbito jurídico. Esta excepcionalidad significa que la TAP debe utilizarse cuando existen razones fuertes para ello y además, debe serlo en forma proporcionada. Su aplicación, también es residual o en defecto de norma expresa que solucione el caso. Y por último, su concurso es supletorio en ausencia de otros instrumentos jurídicos de protección de los derechos del tercero afectado ${ }^{45}$.

La aplicación de la TAP en asuntos laborales que se defiende en este artículo, supone pues, que debe recurrirse a ella en forma excepcional, residual, supletoria y proporcionadamente.

2. Precisado lo anterior, no se niega que la aplicación de la TAP reconoce en la irrenunciabilidad de los derechos (orden público, bienes indisponibles), una importante limitación que, sin embargo, puede ser superada porque todos los derechos reconocen límites.

En efecto: la buena fe, como se ha venido mostrando desde diversos ángulos a lo largo de este trabajo, es un límite al ejercicio de los derechos. Los derechos de los trabajadores y de los empleadores, siendo derechos, pueden ser limitados por la buena fe. Es indiscutido que el Principio de la Buena Fe es uno de los principios rectores del ordenamiento jurídico chileno. Aunque sea obvio decirlo, no podemos dejar de insistir que el Derecho del Trabajo es parte del ordenamiento jurídico chileno y que, por lo tanto, también se encuentra influenciado normativamente por el principio de buena fe.

Por lo anterior, hacer argumentativamente extensiva la aplicación del principio de la buena fe, del ordenamiento general a un ordenamiento jurídico particular como lo es el laboral, no implica lógicamente -como ha sugerido un autor-, incurrir en la falacia de la división, porque no se está atribuyendo las cualidades del todo a una

45 Corral (2010b) pp. 104-106. 
parte de él ${ }^{46}$. La división del ordenamiento jurídico en subordenamientos, es metodológica. El ordenamiento jurídico es uno. El venire es una forma de concreción y/o aplicación del principio de la buena fe; principio que constituyente del ordenamiento jurídico chileno.

3. Estamos ciertos que el tema se complejiza a nivel de derechos fundamentales porque los límites a los derechos fundamentales solo pueden provenir de otros derechos fundamentales. Entonces bien, si la irrenunciabilidad de los derechos laborales es presentada como el gran obstáculo para la aplicación de la TAP en el Derecho del Trabajo, razonable resulta preguntarse, primero, si es un derecho fundamental.

Es indiscutido en la doctrina y en la jurisprudencia que el principio de protección al trabajador es un derecho fundamental entre otras razones, porque así expresamente lo reconoce 19 No 6 de la C.P.R. Esta conceptualización, ha sido reconocida muy recientemente por la jurisprudencia del TC, cuando ha dicho que tal norma "no se limita solo a garantizar las libertad de elección y de contratación laboral, sino que, al incluir la garantía constitucional el reconocimiento expreso de la libertad de trabajo y su protección, la constitución extiende la protección al trabajo mismo, en atención al compromiso inseparable de respeto a la dignidad del trabajador en la forma que efectúa su labor y a la ineludible función social que cumple el trabajo. En consecuencia, la constitución también protege al trabajo propiamente tal, no consagrando el derecho al trabajo en términos generales, pero sí derechos que constituyen elementos fundamentales de este y que pueden exigirse del Estado" ${ }^{\prime 7}$.

Ahora bien, la irrenunciabilidad de los derechos laborales no se encuentra consagrada en la C.P.R., pero sí, en el Código del Trabajo. Esta circunstancia impide considerar la irrenunciabilidad de los derechos laborales como un derecho fundamental. Lo que ordena la C.P.R. no es la irrenunciabilidad de los derechos laborales, sino solo la protección del trabajo y del trabajador. La irrenunciabilidad de los derechos laborales - "mientras subsista el contrato de trabajo" - es una forma de protección del trabajo y del trabajador compatible con la C.P.R., pero sin embargo, no es la única forma de protección. Puede protegerse un estado normativo sin que sea condición suficiente la irrenunciabilidad de los derechos que confiere tal estado (en lo constitutivo y en lo derivativo), y con menor razón cuando se ejerce abusivamente.

En efecto, dado que la buena fe es un principio constitutivo del ordenamiento jurídico $^{48}$, el ejercicio de los derechos laborales no puede implicar ni lógica ni materialmente, una permisión del uso abusivo de tal clase de derechos, pues aquello significaría erosionar las bases del ordenamiento. $Y$ es que estamos en presencia de dos cuestiones analíticamente distintas, a saber: un estado normativo mandado por la ley es la irrenunciabilidad de los

\footnotetext{
46 Gandulfo (2012) p. 6.

47 REQUERIMIENTO DE INAPLICABILIDAD POR INCONSTITUCIONALIDAD PRESENTADO POR EL SEGUNDO JUZGADO DE LETRAS de Talagante Respecto del artículo 26 bis del Código del TRabajo, en los aUtos laborales RIT 103-10-T.L (2011).

48 Una defensa de la doctrina que ha caracterizado la buena fe como derecho fundamental, en Ramírez (2003) pp. 739-756.
} 
derechos laborales, que por cierto e indudablemente no se cuestiona y se asume dogmáticamente también como premisa en este trabajo; y otro estado normativo mandado -a nivel constitutivo por el ordenamiento-, completamente distinto, es que el derecho debe ejercerse no abusivamente, incluso, si es irrenunciable; porque si se ejerce abusivamente potencialmente puede causarse daño. Y si así fuere, entonces se generaría la paradoja jurídica consistente en que, ora en nombre de la irrenunciabilidad de los derechos laborales (que persiguen proteger a una parte), se estaría legitimando el causar daño a la otra, que sí ha ejercido de buena fe sus derechos.

Este planteamiento ha sido recogido de algún modo en una sentencia de casación en el fondo de la Corte Suprema que, en lo pertinente, y en contra de las pretensiones de un trabajador que era socio y gerente de la empresa demandada, dijo: "Décimo: Que para dirimir dicho conflicto, ha de señalarse, en primer lugar, que, en la especie, ha quedado como hecho establecido en la sentencia de que se trata, que el demandante era, además de gerente general de la demandada, socio y director de la misma y que carecía -en la calidad de gerente general- conforme al mandato que le fue conferido, de la facultad de autocontratación y, en segundo lugar, debe preferirse el principio básico de la buena fe, por cuanto, en el caso se trata de un demandante que ostenta, al unísono, las calidades de trabajador y empleador, es decir, sobre él recaía la obligación de escriturar, en la forma pertinente, su contrato de trabajo y al no hacerlo, en su favor, no pueden presumirse como estipulaciones del convenio las que él mismo declara, de manera que la presunción analizada no recibe aplicación en este caso y, por ende, no puede estimarse que la remuneración pactada sea la que ha indicado el actor en su demanda, aun cuando el monto señalado haya sido el que percibió durante, a lo menos, un año, ya que la gestión de la empresa le había sido confiada al demandante" ${ }^{29}$.

El caso es extremo, por cierto (ya que la TAP siempre se aplica a esa clase de casos: difíciles, penumbrales). Se justifica la derrota del principio de protección al trabajador porque quien lo esgrime en su defensa (en clave de irrenunciabilidad del derecho de presunción de verdad sobre las estipulaciones contractuales que declara el trabajador $)^{50}$, lo hace de mala fe, ya que la posición de control que ejercía sobre la administración jurídica de la demandada, no puede sino conducir a esa decisión. El demandante ejerce los derechos laborales en forma abusiva porque pretende que se le reconozca una posición jurídica que no debe ser protegida conforme al mérito de la causa.

\section{CONCLUSIONES}

La buena fe es un principio básico que constituye y sustenta el ordenamiento jurídico y que, bajo diversas configuraciones, se manifiesta en todos sus sectores. Como todo principio, presenta un alto grado de indeterminación en sus supuestos fácticos y en sus

\footnotetext{
49 STERNSDORFF SCHLESINGER, RALPH CON MANASPLAST S.A. (2003). Un caso similar y con aplicación de la TAP como obiter dicta (de un gerente de administración que demandó nulidad de despido por no pago de cotizaciones previsionales): Opazo Corvalan, Pablo con EMPRESAs AXis GROUP S.A. y ECONOTET S.A. (2007).

50 Artículo $9^{\circ}$ del Código del Trabajo.
} 
efectos. En este orden de ideas, la TAP es una doctrina que concretiza el principio de protección a la buena fe.

La jurisprudencia analizada utiliza la TAP como obiter dicta y, cuando lo hace como ratio decidendi, nunca es el único argumento para decidir la litis, sino que es una pieza más de un argumentación compleja, en términos tales que es posible afirmar que la TAP es aplicada como ratio decidendi compleja y débil. Sin duda que esta constatación no es trivial, puesto que obliga al intérprete de la jurisprudencia a reparar en esa cuestión, para calibrar su crítica.

Se ha advertido que la incorporación de la TAP en el discurso jurisdiccional no aparece justificada paso a paso y que por tanto las sentencias en cuestión, presentarían en ese sentido, déficit argumentativos. Sin embargo, y por otra parte, dado que los autores que han criticado esas sentencias no utilizan herramientas de análisis de precedentes jurisprudenciales, sus observaciones a los fallos, también presentarían las mismas debilidades.

Más allá de lo justificado o no que puedan resultar las aplicaciones particulares que la CS ha hecho de la TAP en sus sentencias laborales, se estima que in abstracto y a priori, no existe impedimento para que, en general, pudiera llegar a serlo en el derecho del Trabajo chileno. Porque, sin perjuicio de que no existe una prohibición expresa o tácita en tal sentido, también se mostró que la aludida especialidad histórica del derecho del trabajo que esgrimen sus principales críticos, no es razón suficiente para impedir que, en casos difíciles, pudiera restársele eficacia a ciertas conductas de los trabajadores que contradicen lo actuado en el pasado.

La irrenunciabilidad de los derechos laborales no es un obstáculo insuperable para la aplicación de la TAP en dicho ámbito jurídico, ya que el ejercicio de todo derecho reconoce límites. Un estado normativo mandado por la ley es la irrenunciabilidad de los derechos laborales, que por cierto no se cuestiona y se ha asumido dogmáticamente en este trabajo; y otro estado normativo mandado por la ley, completamente distinto, es que el derecho laboral debe ejercerse no abusivamente, incluso, si es irrenunciable. El tema que debe ser dilucidado a continuación, por consiguiente, es la determinación de las condiciones fácticas y jurídicas que tornarían abusivo el ejercicio de un derecho laboral irrenunciable, lo cual, por cierto, es caso a caso, conforme el mérito de los antecedentes, siendo necesaria la realización de estudios futuros que contribuyan a la creación de conocimiento jurídico que permita proponer tipologías de aplicabilidad.

\section{BIBLIOGRAFÍA CITADA}

Ackerman, Mario E. y Tosca, Diego M. (2005): Tratado de derecho del trabajo, Tomo II La relación individual de trabajo, Tomo I (Buenos Aires, Rubinzal-Culzoni Editores).

AleXY, Robert (2007): Teoría de los derechos fundamentales (Madrid, Centro de Estudios Políticos y Constitucionales, traducción y estudio introductorio Carlos Bernal Pulido). Atienza, Manuel y Ruiz Manero, Juan (2007): Las piezas del Derecho. Teoría de los enunciados jurídicos (4⿳a reimpresión, Barcelona, Ariel, 2a edición). 
Barros Bourie, Enrique (1999): "Límites de los Derechos Subjetivos Privados. Introducción a la Doctrina del Abuso de Derecho", Revista Derecho y Humanidades, Universidad de Chile, No 7: pp. 11-37.

BarRos Bourie, Enrique (2006): Tratado de responsabilidad extracontractual (Santiago, Editorial Jurídica de Chile).

Bernal Fandiño, Mariana (2010): "La doctrina de los actos propios y la interpretación del contrato", Vniversitas (Colombia) N 120: pp. 253-270.

Blasco Pellicer, Ángel (1995): La individualización de las relaciones laborales (Madrid, Consejo Económico y Social).

Busnelli, Frascesco Donato (2002): "Notas en temas de buena fe y equidad", Revista Di Diritto Dell'Integrazione e Unificazione del Diritto in Europa e in America Latina No13: pp. 99-121.

Borda, Alejandro (2005): La teoría de los actos propios (Buenos Aires, LexisNexis, cuarta edición).

Brito Guzmán, Alejandro (2002): "La buena fe en el Código Civil de Chile", Revista Chilena de Derecho, vol. 29, N 1: pp. 11-23.

CAAmaño Rojo, Eduardo (2009a): "Análisis crítico sobre la aplicación de la doctrina de los actos propios en materia laboral", Revista de Derecho de la Pontificia Universidad, XXXII-2009, semestre I: pp. 261-280.

CAamaño Rojo, Eduardo (2009b): "Otra vuelta de tuerca a la jurisprudencia de la Corte Suprema sobre la doctrina de los actos propios en la materia laboral", Revista de la Sociedad Chilena de Derecho del Trabajo y de la Seguridad Social, No 4: pp. 37-53.

CONde Marín, Emilia (2007): La buena fe en el contrato de trabajo (Madrid, La Ley).

García de Enterría, Eduardo (1956): "La doctrina de los actos propios y el sistema de lesividad", Revista de Administración Pública, No 20: pp. 69-80.

Córdoba M., Marcos (2009): Tratado de la buena fe en el Derecho, Tomos I y II (Buenos Aires, La Ley, segunda reimpresión).

Corral Talciani, Hernán (2009): "La aplicación jurisprudencial de la buena fe objetiva en el ordenamiento civil chileno", en: Córdova M., Marcos Tratado de la buena fe en el Derecho, Tomo II (Buenos Aires, La Ley, segunda reimpresión) pp. 207-224.

Corral Talciani, Hernán (2010a): "La raíz histórica del adagio "venire contra factum propium non valet", en CORRAL TALCIANI, Hernán, Venire contra factum propium. Escritos sobre la fundamentación, alcance y límites de la doctrina de los actos propios (Santiago, Universidad de los Andrés/Facultad de Derecho) pp. 19-33.

Corral Talciani, Hernán (2010b): "La doctrina de los actos propios en el derecho de familia chileno", en: CoRral TAlCiani, Hernán, Venire contra factum propium. Escritos sobre la fundamentación, alcance y limites de la doctrina de los actos propios (Santiago, Universidad de los Andrés/Facultad de Derecho) pp. 105-106.

Cross, Rupert y Harris, J.W. (2004): Precedent in English Law, (Oxford, Clarendon Press, reprinted, ebook)

Chacana Matkovic, Mario (2011): "Los efectos de la Ley No 19.631 en las relaciones laborales decretadas por sentencias judiciales: ¿una solución de equidad de la jurisprudencia o un descalabro jurídico?", Actualidad Laboral, octubre, No XCI: pp. 5-16. 
De la Villa GiL, Luis Enrique (2003): "El principio de adecuación social y los conceptos jurídicos indeterminados en el derecho del trabajo” en DE LA VILla Gil, Luis Enrique y López Cumbre, Lourdes (directores). Los principios del derecho del trabajo (Madrid, centro de Estudios Financieros) pp. 393-416.

DE LOS Mozos, José Luis (1965): El principio de la buena fe: sus aplicaciones prácticas en el derecho civil español (Barcelona, Bosch).

Díez-PicAzo, Luis (1963): La doctrina de los actos propios. Estudio crítico sobre la jurisprudencia del Tribunal Supremo (Barcelona, Editorial Bosch).

Díez-Picazo, Luis (2011): Fundamentos del Derecho Civil Patrimonial I. (Pamplona, Civitas/Thomson Reuters, sexta reimpresión).

Escudero, J.F., Frigola, J. y corbella, T. (1996): El principio de la buena fe en el contrato de trabajo (Barcelona, Bosch).

Ekdhal Escobar, María Fernanda (1989): La doctrina de los actos propios. El deber jurídico de no contrariar conductas propias pasadas (Santiago, Editorial Jurídica de Chile).

Fueyo Laneri, Fernando (1990): Instituciones de derecho civil moderno (Santiago, Editorial Jurídica de Chile).

Gajardo Harboe, María Cristina (2010): "Buena Fe y Derecho del Trabajo”, Revista Chilena de Derecho del Trabajo y de la Seguridad Social, vol. 1, No 2: pp. 15-31.

Gandulfo R., Eduardo (2005): "La aplicación del Principio 'Venire contra Factum Propium Non Valet'. Un caso de Vulgarismo Jurídico”, Revista Chilena de Derecho, vol. 32, $\mathrm{N}^{\circ}$ 2: pp. 363-374.

GANDUlfo R., Eduardo (2012): "La prohibición de ir contra los propios actos y el contexto de orden público. (Una aproximación con el Derecho del Trabajo en el caso Pacareu con Universidad Mayor)", La Razón del Derecho, Revista Interdisciplinaria de Ciencias Jurídicas, No 3: pp. 1-24.

Garner A., Bryan (2004): Black's law dictionary (Minnesota Thomson West, octava edición, segunda reimpresión).

García Viña, Jordi (2001): La buena fe en el contrato de trabajo (Madrid, Centro Económico y Social).

Gumucio Rivas, Juan Sebastián y corvera vergara, Diego (2006): “Comentarios a una Jurisprudencia. La Doctrina de los actos propios y el Derecho del Trabajo", Revista Laboral Chilena, No 151: pp. 72-79.

Guzmán Brito, Alejandro (2002): "La buena fe en el Código Civil de Chile", Revista Chilena de Derecho, vol. 29, No 1: pp. 11-23.

Guzmán Brito, Alejandro (2009): "La buena fe en el Código Civil de Chile", en Córdova, Marcos Tratado de la buena fe en el Derecho, Tomo II (Buenos Aires, La Ley, segunda reimpresión) pp. 77-94.

Irureta Uriarte, Pedro (2006): Constitución y orden Público Laboral. Un análisis del art. 19 no 16 de la constitución chilena (Santiago, Universidad Alberto Hurtado, Facultad de Derecho, Colección de Investigaciones Jurídicas, No 9).

IruReta Uriarte, Pedro (2011a): "Vigencia del principio de la buena fe en el derecho del trabajo chileno", Revista Ius et Praxis, Año 17, No 2: pp. 133-188. 
Jaramillo Jaramillo, Carlos Ignacio (2012): La doctrina de los actos propios en el ámbito contractual. -Significado y proyección de la regla venire contra factum propium non valet(Salamanca, Universidad de Salamanca, Tesis Doctoral, dirigida Dr. D. Eugenio Llanos Pombo).

Larenz, Karl (1978): Derecho Civil. Parte General (Madrid Editorial Revista de Derecho privado-Editoriales de Derecho Reunidas, traducción y notas de Miguel Izquierdo y Macías-Picavea).

Legarre, Santiago y Rivera, Julio César (2006): "Naturaleza y dimensiones del Stare Decisis", Revista Chilena de Derecho, vol. 33, N 1: pp. 109-124.

López Medina, Diego Eduardo (2006): El Derecho de los Jueces (Bogotá, Universidad de los Andes \& Legis).

López Mesa, Marcelo (2009): "La doctrina de los actos propios: esencia y requisitos de aplicación”, Revista Universitas Bogotá, № 119: pp. 189-222.

López Mesa, Marcelo y Rogel Vide, Carlos (2005): La doctrina de los actos propios (Madrid, Editorial Reus).

López Santa María, Jorge (1985): "Intereses devengados por indemnización contractual de perjuicios. Doctrina de los actos propios o estoppel", Revista de Derecho y Jurisprudencia, vol. LXXXII, No 2: pp. 33-52.

López Oneto, Marcos Eduardo (2013): El principio de protección a la fuente del empleo en Chile. Pasos hacia un derecho del trabajo bidireccional (Santiago, ThomsonReuters/LegalPublishing).

Martín Valverde, Antonio (1990): "El discreto retorno del arrendamiento de servicios", en Montoya Melgar, Alfredo, Martín Valverde, Antonio y Rodríguez-Sañudo, Fermín (coordinadores), Cuestiones actuales de Derecho del Trabajo (Madrid, Ministerio del Trabajo y Seguridad Social).

Martín Valverde, Antonio (2003): "Principios y reglas en el Derecho del Trabajo. Planteamiento teórico y algunos ejemplos”, en De la Villa Gil, Luis Enrique y López Cumbre, Lourdes (directores). Los principios del derecho del trabajo (Madrid, Centro de Estudios Financieros) pp. 39-72.

Monereo Pérez, José Luis (1996): Introducción al nuevo derecho del trabajo (Valencia, Tirant lo Blanch)

Mangarelli, Cristina (2008): "El Derecho del Trabajo y su relación con el Derecho Civil", Revista Latinoamericana de Derecho Civil, No 7: pp. 105-123.

Montoya Melgar, Alfredo (2001): La buena fe en materia laboral (Madrid, Tecnos).

Neme Villareal, Martha Lucía (2010): La buena fe en el derecho romano. La extensión del deber de actuar conforme a buena fe en materia contractual (Bogotá, Roma e America, Diritto Romano Comune, Monografie 3, Universidad Externado de Colombia).

Ojeda Avilés, Antonio (2010): La deconstrucción del Derecho del Trabajo (Madrid, La Ley/ Grupo Wolters Kluwer).

Opazo Mulack, Raimundo (2008): "La doctrina de los actos propios y el Derecho Laboral", Revista del Abogado, № 43: pp. 32-36. 
Opazo Mulack, Raimundo (2009): "La doctrina de los actos propios y su procedencia en la solución de conflictos laborales”, Estudios Laborales, Revista de la Sociedad Chilena de Derecho del Trabajo y de la Seguridad Social, No 4: pp. 69-88.

Palomeque López, Manuel Carlos (2011): Derecho del Trabajo e ideología (séptima edición, Madrid, Tecnos).

Pardo de Carvallo, Inés (1992): "La doctrina de los actos propios", Revista de Derecho de la Universidad Católica de Valparaíso, XIV: pp. 49-69.

Peñailillo Arévalo, Daniel (2008): Obligaciones. Teoría general y clasificaciones. La resolución por incumplimiento (Santiago, Editorial Jurídica de Chile)

Peñailillo Arévalo, Daniel (2009): Los bienes. La propiedad y otros derechos reales (Santiago, Editorial Jurídica de Chile).

Plá Rodríguez, Américo (1990): Los principios del Derecho del Trabajo (Buenos Aires, Ediciones Depalma, tercera edición).

Puig Brutau, José (1951): Estudios de Derecho Comparado: la doctrina de los actos propios (Barcelona, Ariel).

Ramírez ArRaYÁs, José Antonio (2003): "Interpretación constitucional y principio de buena fe", Estudios Constitucionales, vol. 1, N 1: pp. 739-756.

Rivas GuZMÁn, Ramón (1991): "La doctrina de los actos propios y el reglamento interno de la empresa", en Barros Bourie, Enrique (coordinación), Contratos (Santiago, Editorial Jurídica de Chile) pp. 190-217.

Rodríguez-Piñero Royo, Miguel (1992): "La huida del Derecho del Trabajo", Relaciones Laborales, No 1: pp. 85-94.

Romero Seguel, Alejandro (2003): "Comentario a la sentencia de la Corte Suprema, 9 de mayo de 2001. El principio de la buena fe procesal y su desarrollo en la jurisprudencia, a la luz de la teoría de los actos propios", Revista Chilena de Derecho, vol. 30, № 1: pp. 167-172.

Romero Seguel, Alejandro (2010): "El acto propio en materia arbitral: algunos límites probatorios para su aplicación”, Cuadernos de Extensión Jurídica, Universidad de los Andes, No 18: pp. 69-79.

Romero Seguel, Alejandro (2011): "La discriminación judicial como nuevo error decisorio litis en el proceso chileno", Revista Chilena de Derecho, vol. 38, No 2: pp. 339-348.

Salah Abusleme, María Agnes (2008): "La doctrina de los actos propios y de la protección a la apariencia: una mirada comparativa", Revista del Magister y Doctorado en Derecho Facultad de Derecho de la Universidad de Chile, No 2: pp. 189-202.

Sierra Herrero, Alfredo. (2010): "Las teoría de los actos propios en el ámbito laboral” en Corral Talciani, Hernán (edit.), Venire contra factum propium. Escritos sobre la fundamentación, alcance y límites de la doctrina de los actos propios (Santiago, Universidad de los Andes/Facultad de Derecho) pp. 141-151.

Summers, Robert (1982) "The General Duty of Good Faith: Its Recognition and Conceptualization”, Corn. L. Rev., No 67: pp. 810-840.

Stitchkin López, David León (2009): Estudio y análisis jurisprudencial de la teoría de los actos propios en el Derecho del Trabajo, Memoria para optar al grado de Licenciado en Ciencias Jurídicas y Sociales, Facultad de Derecho, Universidad de Chile. 
Tapia Guerrero, Francisco (2005): “Trabajo subordinado y tutela de los derechos laborales", en Bronstein S., Arturo et al. La subordinación o dependencia en el contrato de trabajo en el proceso de transformación de la empresa (Gobierno de Chile, Dirección del Trabajo/LexisNexis) pp. 211-235.

Ugarte Cataldo, José Luis (2008): "Los actos propios en materia laboral o guía de cómo inventarse una Doctrina”, Revista Laboral Chilena, No 72: pp. 90-93.

Ugarte Cataldo, José Luis (2013): Derechos Fundamentales en el contrato de trabajo (Santiago, LegalPublishing/Thomson Reuters).

WIEACKER, Franz (1977) El principio general de buena fe (trad. J. Carro, Madrid, Civitas).

WhitTaker, Simon (2008): "El precedente en el derecho inglés: una visión desde la ciudadela", Revista Chilena de Derecho, vol. 35, N 1: pp. 37-83.

Wittgenstein, Ludwig (2008): Investigaciones filosóficas (cuarta edición, Barcelona, Instituto de Investigaciones Filosóficas UNAM Editorial Crítica).

Zimmermann, Reinhard y Whittaker, Simon (2008): Good Faith in European Contract Law (Cambridge, Cambridge University Press, digitally printed version).

\section{JURISPRUDENCIA CITADA}

Empresa de MANufacturas de Cobre S.A. (Madeco S.A.) con Sindicatos 1 y 2 de la EMPResa DE MANufacturas de Cobre S.A. (1998): Corte Suprema (nulidad absoluta de cláusulas de contrato colectivo), recurso de casación en el fondo rechazado, Rol No 286-1998, en Stitchkin López, David León (2009): "Estudio y análisis jurisprudencial de la teoría de los actos propios en el Derecho del Trabajo”, memoria para optar al grado de Licenciado en Ciencias Jurídicas y Sociales, Facultad de Derecho, profesor guía Ricardo Juri Sabag, Universidad de Chile, pp. 151-162.

AzÓCAR TAPIA, LUIS CON AZÓCAR S.A. (2000): Corte de Apelaciones de Santiago, 27 de septiembre de 2000 (recurso de casación en la forma y confirma sentencia en apelación), Rol No 913-2000, en Base Jurisprudencial Corte Apelaciones de Santiago, disponible en: http://www.poderjudicial.cl/

STERNSDORFF SCHLESINGER, RALPH CON MANASPLAST S.A. (2003): Corte Suprema, 17 de marzo de 2003 (despido injustificado, presunción artículo 9 del Código del Trabajo), recurso de casación en el fondo acogido, R.D.J., 2003, segunda parte, sección tercera, pp. 24-29.

Labra Guerrero, Franklin del Carmen con Ingenieros Consultores Asociados S.A (2003): Corte Suprema, 29 de marzo de 2005 (recurso de casación fondo y forma rechazado), Rol No 3.594-03, en Base Jurisprudencial Corte Suprema, disponible en: http://www. poderjudicial.cl/

Muñoz Vilches, Paola Andrea con Inmobiliaria El Rebaño Limitada (2005): Corte Suprema, 27 de octubre de 2005 (despido injustificado y fuero maternal), recurso casación en el fondo rechazado, Rol No3.991-04, en Base Jurisprudencial Corte Suprema, disponible en: http://www.poderjudicial.cl/

Gonzalez Palma, Máximo Javier con Ingeniería, Servicios y Transportes Riam Ltdda. (2006): Corte Suprema, 4 de abril de 2006 (recurso casación forma y fondo rechazado) 
Rol No 3.108-2005, en Base Jurisprudencial Corte Suprema, disponible en: http://www. poderjudicial.cl/

Gumucio Rivas, Juan con Empresa Metropolitana de Obras Sanitarias (2006): Corte Suprema, 26 de abril de 2006, recursos de casación fondo y forma, Rol No 3.627-2004, en Base Jurisprudencial Corte Suprema, disponible en: http://www.poderjudicial.cl/

Mujica Varas, Eduardo con Corporación de TeleVisión Universidad Católica (2006): Corte Suprema, 30 de agosto de 2006 ,(recursos casación fondo y forma rechazados) Rol No 981-2005, en Base Jurisprudencial Corte Suprema, disponible en: http://www. poderjudicial.cl/

Alcayaga Sasso, Juan con Corporación de Televisión Universidad Católica (2006): Corte Suprema, 25 de octubre de 2006 (recurso casación en el fondo acogido) Rol No 7712005, en Base Jurisprudencial Corte Suprema, disponible en: http://www.poderjudicial.cl/

Escalona Pino, Simón con Superintendencia de Administradora de Fondos de Pensiones (2006): Corte Suprema, 27 de noviembre de 2006 (recurso de casación en el fondo rechazado) Rol No 397-2005, en Base Jurisprudencial Corte Suprema, disponible en: http://www.poderjudicial.cl/

López Rediman, LuIS CON I.N.P (2006): Corte Suprema, 4 de diciembre de 2006 (recurso de casación en el fondo acogido) Rol No 545-06, en Base Jurisprudencial Corte Suprema, disponible en: http://www.poderjudicial.cl/

isela Ferlín, Néstor Ítalo con Corporación de Televisión Universidad Católica de Chile (2006): Corte Suprema, 20 de diciembre de 2006 (recurso de casación en el fondo acogido) Rol No 2.450-05, en Base Jurisprudencial Corte Suprema, disponible en: http:// www.poderjudicial.cl/

Monasterio Riquelme, Eduardo Antonio con red de Televisión Chile visión (2007): Corte Suprema, 25 de enero de 2007 (recurso de casación en el fondo acogido) Rol No 5.31605, en Base Jurisprudencial Corte Suprema, disponible en: http://www.poderjudicial.cl/

inspector Provincial del Trabajo de Valdivia con Aserraderos Pallaco S.A.(2007): Corte Suprema, 26 de abril de 2007 (invalidación de oficio de la sentencia) Rol No 3.101-2005, en Base Jurisprudencial Corte Suprema, disponible en: http://www.poderjudicial.cl/

Anabalón Barrientos, Héctor y otros con Forestal RuCA Pequen S.A. (2007): Corte Suprema, 26 de abril de 2007 (invalidación de oficio de la sentencia) Rol No 3.168-2005, en Base Jurisprudencial Corte Suprema, disponible en: http://www.poderjudicial.cl/

Bustos Rabilar, José Rafael con Corporación de TeleVisión Universidad Católica (2007): Corte Suprema, 27 de abril de 2007 (recurso de casación en la forma acogido) Rol No 5.032-05, en Base Jurisprudencial Corte Suprema, disponible en: http://www.poderjudicial.cl/

Opaco Corbalan, Jaime con Axis Grupo S.A. y EConet S.A: (2007): Corte Suprema, 29 de agosto de 2007 (nulidad de despido, recurso de casación en el fondo rechazado), Rol No 4540-2006, en Base Jurisprudencial Corte Suprema, disponible en: http://www.poderjudicial.cl/

Santander Lizana, María con Corporación de TeleVisión Universidad Católica (2007): Corte Suprema, 10 de octubre de 2007 (recurso de casación en el fondo acogido) Rol No 3.906-06, en Base Jurisprudencial Corte Suprema, disponible en: http://www.poderjudicial.cl/ 
KLiche Antonini, Walter con Corporación de TeleVisión Universidad Católica (2007) S Rol No 3.906-06, enoctubre de 2007 (286-1998, A.) con Sindicatos 1 y 2 de la Empresa de Manufacturas de Cobre S.A. : Corte Suprema, 17 de octubre de 2007 (recurso de casación acogido) Rol No 5.687-06, en Base Jurisprudencial Corte Suprema, disponible en: http://www.poderjudicial.cl/

muñoz Calderón, María Soledad con Caritas Chile (2008): Corte Suprema, 10 de junio de 2008 (recurso de casación en el fondo rechazado) Rol No 2.320-08, en Base Jurisprudencial Corte Suprema, disponible en: http://www.poderjudicial.cl/

Pacareu Gay, Natalia con Universidad Mayor (2008): Corte Suprema, 4 de noviembre de 2008 (recurso de casación en el fondo acogido) Rol No 5.129-08, en Base Jurisprudencial Corte Suprema, disponible en: http://www.poderjudicial.cl/

Yánez ArRiagada, Ximena Alejandra con Campos Deportivos Llancolen S.A. (2008): Corte Suprema, 31 de diciembre de 2008 (configuración de relación jurídica laboral), recurso de casación en el fondo acogido, Rol No 7.178-08, en Base Jurisprudencial Corte Suprema, disponible en: http://www.poderjudicial.cl/

REQUERIMIENTO DE INAPLICABILIDAD POR INCONSTITUCIONALIDAD PRESENTADO POR EL SEGUNDO Juzgado de Letras de TALAGante Respecto del artículo 26 bis del Código del TRABajo, EN LOS AUTOS LABORALES RIT 103-10-T.L SOBRE DENUNCIA DE TUTELA DE DERECHOS FUNDAMENTALES Y COBRO DE PRESTACIONES E INDEMNIZACIONES SUSTANCIADOS ANTE EL SEGUNDO JuZGADO DE LETRAS DE TALAGANTE (2011): Tribunal Constitucional, acogido, 26 de julio de 2011.

Godoy CON RED Televisiva Megavisión S.A. (2012): Corte Suprema, 15 de enero de 2013 (recurso de unificación declarado inadmisible) en Base Jurisprudencial Corte Suprema, disponible en: http://www.poderjudicial.cl/ 
